\title{
Harmal Extract Induces Apoptosis of HCT116 Human Colon Cancer Cells, Mediated by Inhibition of Nuclear Factor- $\varkappa B$ and Activator Protein-1 Signaling Pathways and Induction of Cytoprotective Genes
}

\author{
Ayman I Elkady ${ }^{1,2}$, Rania A Hussein ${ }^{3,4}$, Sufian M El-Assouli1,5*
}

\begin{abstract}
Background: Colorectal cancer (CRC) is a major cause of morbidity and mortality, being the second most common type of cancer worldwide in both men and women. It accounts yearly for approximately $9 \%$ of all new cases of cancers. Furthermore, the current chemotherapeutic regimens seem unsatisfactory, so that exploration of novel therapeutic modalities is needed. The present study was undertaken to investigate the inhibitory effects of a crude alkaloid extract (CAERS) of a medicinal herb, Rhazya stricta, on proliferation of CRC HCT116 cells and to elucidate mechanisms of action. To achieve these aims, we utilized MTT, comet, DNA laddering and gene reporter assays, along with Western blot and RT-PCR analyses. Results: We found that CAERS inhibited cell proliferation and induced apoptotic cell death in HCT116 cells. Hallmarks of morphological and biochemical signs of apoptosis were clearly evident. CAERS down-regulated DNA-binding and transcriptional activities of NF- $\varkappa \mathrm{B}$ and AP-1 proteins, while up-regulating expression of the Nrf-2 protein. It also down-regulated expression levels of the ERK MAPK, Bcl-2, cyclin D1, CDK-4, survivin and VEGF and up-regulated levels of Bax, caspase-3/7 and -9, p53, p21, Nrf-2. Markedly, it promoted mRNA expression levels of cytoprotective genes including the hemeoxygenase-1, NAD(P)H quinine oxidoreductase 1 and UDP-glucuronyltransferase. Conclusions: These findings indicate that CAERS exerts antiproliferative action on CRC cells through induction of apoptotic mechanisms, and suggest CAERS could be a promising agent for studying and developing novel chemotherapeutic agents aimed at novel molecular targets for the treatment of CRC.
\end{abstract}

Keywords: Apoptosis - oncogenes - cytoprotective genes - transfection - DNA damage - caspase-3/7

Asian Pac J Cancer Prev, 17 (4), 1947-1959

\section{Introduction}

Colorectal cancer (CRC) is among the most common malignant diseases worldwide and therapy is still difficult at advanced stages. Typically, the standard therapy consists of 5-fluorouracil in combination with irinotecan, oxaliplatin or levamisole (Ragnhammar et al., 2001). In addition antibodies targeting the epidermal growth factor receptor and the vascular endothelial growth factor have been introduced and improved prognosis for CRC patients (Eng, 2010). In spite of this progress, therapy of advanced CRC is still not satisfactory due to side effects, and toxicity of cytotoxic drugs, as well as inherent mechanisms of therapy resistance in CRC tumor cells (Rabik and Dolan, 2007).

A recognized mechanism for the development of colorectal carcinoma is a progressive inhibition of apoptosis (Yang et al., 2009). Apoptosis is a physiological cell-suicide process that plays an important role during the development of multicellular organisms and is critical for the maintenance of tissue homeostasis (Hanahan and Weinberg, 2011). Apoptosis is tightly regulated by a number of distinct pathways and can be induced after a cell has experienced DNA damage (Dunkern et al., 2001). However, most cancer cells can block apoptosis, which allows them to survive and grow rapidly and uncontrollably. Therefore, regulation of apoptosis has become an area of extensive study in cancer research and the induction of apoptotic cell death has been considered an ideal way of eliminating precancerous and/or cancerous cells (Justin et al., 2008). Apoptosis is characterized by a series of distinct morphological and biochemical alterations to cells such as DNA fragmentation, chromatin condensation, cell shrinkage, plasma membrane blebbing, translocation of phosphatidyl serine to the outer cell membrane proteolytic activation of caspases (Kokileva, 
1994), cytochrome c release from mitochondria and the activation of caspases (Wong, 2011). The typical executioners of apoptosis are the proteolytic enzymes called caspases; these caspases are grouped into initiator caspases and execution caspases (Wong, 2011). Caspase-3 in particular is one of the key executioners of apoptosis and is partially or wholly responsible for the proteolytic cleavage of many proteins and DNA fragmentation, leading to cell death (Saraste and Pulkki, 2000). Initiator caspases are activated by way of 2 classical pathways: the extrinsic (death receptor) and the intrinsic (mitochondrial) (Wong, 2011).Although the specific details are not yet known, it is generally accepted that a variety of stimuli such as stress and drugs trigger apoptosis through pathways involving the mitochondria, which serve as a vital death signal integrator in apoptosis (Wong, 2011). The perturbation of mitochondrial membranes and the consequent release of cytochrome $\mathrm{c}$ appear to be critical events for apoptosis. In addition to caspases, apoptosis is also tightly regulated by protein other families; for example, the proteins Bax and $\mathrm{Bcl}-2$ have opposing roles in initiating mitochondrial dysfunction and modulating apoptosis (Zimmermann et al., 2001). Bcl-2 is associated with the outer mitochondrial membrane, where it plays a pivotal and overriding protective role by preserving mitochondrial structure and function, thereby preventing the onset of a mitochondrial permeability transition and inhibiting the release of cytochrome $\mathrm{c}$ into the cytosol. In contrast, Bax, a dominant-negative inhibitor of Bcl2 , induces a mitochondrial permeability transition and promotes apoptosis (Zimmermann et al., 2001). Thus, when the level of Bax increases, the mitochondrial membrane becomes permeable to cytochrome c. Upon its release from the mitochondria into the cytosol, cytochrome c forms an apoptosome complex with Apaf-1, pro-caspase9and ATP, leading to the cleavage and activation of caspase-9, which in turn activates downstream effector caspases suchas caspase-3/-7. Subsequently, the active executionercaspase-3 cleaves downstream substrates such as poly-(ADPribose) polymerase, which are responsible for the morphological and biochemical changes that are the hallmarks of apoptosis (Saraste and Pulkki, 2000).

Recent studies indicate that identifying naturally occurring chemopreventive substances capable of targeting one or more signaling intermediates leading to induction of apoptosis in cancer cells is considered as a practical approach to reduce the ever-increasing incidence of cancer. In response to thissituation, there is increasing interest in research on medicinal plants in the search for novel agents for cancer treatment/prevention (Aggarwal et al., 2011).To this end, a medicinal herb, Rhazya stricta, can provide mankind with new therapeutic remedies. $R$. stricta belongs to the Apocynaceae family and is an important medicinal species used in indigenous medicinal herbal drugs to cure various diseases in South Asia and the Middle East (Gilani et al., 2007). Extract of $R$. stricta leaves is prescribed in folkloric medicine for the treatment of various disorders such as diabetes, sore throat, helminthesis, inflammatory conditions and rheumatism. In addition, it has been reported that $R$. stricta is a good source of antioxidants (Marwat et al., 2012) and we previously have reported that an aqueous extract of $R$. stricta inhibited cell proliferation and induced apoptotic cell death in the breast cancer cell lines MCF-7 and MDA MB-231 (Baeshen et al., 2012). The herb is particularly rich in alkaloid; this notion is important knowing alkaloids are among the most important active components in natural herbs (Anisz, 2007). In addition, several alkaloids isolated from natural herbs have been shown to exhibit anti-proliferation and anti-metastasis effects on various types of cancers both in vitro and in vivo ( $\mathrm{Lu}$ et al., 2012), and some of these compounds have already been successfully developed into chemotherapeutic drugs, such as camptothecin (Huang et al., 2007) and vinca alkaloids, vincristine and vinblastine (Li et al., 2007). It is worth mentioning that indole alkaloids in $R$. stricta have been found to exhibit numerous biological activities such as antimicrobial and antihypertensive activities and anticancer potentiality (Gilani et al., 2007). Recently, we found that a crude alkaloid extract from $R$. stricta inhibited cell growth in glioblastoma (Elkady et al., 2013) and sensitized human lung cancer cells to cisplatin through induction of apoptosis (Elkady, 2013). Finally, another study demonstrated that alkaloid fraction in $R$. stricta induced activity and expression levels of the chemopreventative enzyme, Nqo1 (El Gendy et al., 2012). In the present study the mechanisms of anti-proliferative and pro-apoptotic effects of crude alkaloid extract from R. stricta on human colorectal carcinoma cells (HCT116) are investigated.

\section{Materials and Methods}

Unless otherwise noted, all chemicals were purchased from Sigma.

\section{Identification of Rhazy a sricta strong alkaloids constituents by HPLC-MS Analysis}

Crude, dry hydro chlorinated strong basic alkaloid fraction of $R$. stricta, was analyzed by Liquid Chromatography-Mass Spectrometry (HPLC-MS) presents in King Fahd Medical Research Centre, King Abdulaziz University to identify the major constituents and differentiate between the alkaloids present in the current $R$. stricta species and other species used elsewhere. The sample was prepared and analysed under the conditions shown in Table 1 (Supplement).

\section{Preparation of Rhazya stricta strong alkaloids (CAERS)}

$R$. stricta was collected from Mecca-Jeddah old road, Saudi Arabia and authenticated at the Herbarium of the Biological Sciences Department in King Abdulaziz University. Collection sites were choosing that reflected different ecological zones. The freshly picked leaves of the plant were air-dried in the shade at room temperature and used for the preparation of the alkaloid extraction. The crude alkaloid extract of $R$. stricta leaves was prepared essentially as previously described (Elkady, 2013). The presence of basic alkaloids in the extract was confirmed by the Wagner's reagent: ( $2 \mathrm{~g}$ of iodine and $6 \mathrm{~g}$ of $\mathrm{KCI}$ in $100 \mathrm{ml}$ of water). Few drops of Wagner's reagent added to equal volume of tested extract, the development of a 
brown precipitates indicate the presence of the alkaloids.

\section{Cell culturing and treatment with CAERS}

The human colorectal carcinoma HCT116 cells were grown in McCoy 5A medium supplemented with $10 \%$ (v/v) fetal bovine serum at $37^{\circ} \mathrm{C}$ in $95 \%$ air and $5 \%$ $\mathrm{CO} 2$. Cells were checked for viability before starting the experiment using the trypan blue assay, and it was about $80 \%$ viable cells. A total of $1.3 \times 10^{4} / \mathrm{cm}^{2}$ cells in triplicates were exposed to basic alkaloids extract at concentrations of $47,63,79$ and $95 \mu \mathrm{g} / \mathrm{cm}^{2}$ for $72 \mathrm{~h}$. After different time periods of incubation (day 1,2 and 3) cell viability was determined by trypan blue dye exclusion test and by tetrazolium salt reagent (WST-1 kit).

\section{Cell viability assessment by tetrazolium salt WST-1 kit}

Cell viability and the effects of CAERS on the growth of HCT116 cells were assessed with the WST-1 Cell Proliferation Assay Kit (Cayman chemicals-USA) following manufacturer's instructions. Briefly, HCT116 cells were seeded onto 96 -well plates $\left(10^{4}\right.$ cells/well $)$ and grown overnight. The cells were then treated with indicated concentrations of the extract and incubated for 24,48 or $72 \mathrm{~h}$. At the end of each incubation, $10 \mu \mathrm{l}$ of freshly prepared WST-1solution was added to each well. Culture medium and WST-1/solution was added in an empty well as a blank for the microtiter plate reader. The absorbance of the treated and untreated samples was measured after 2 hours by (BioTek Synergy HT) micro plate reader, at $450 \mathrm{~nm}$ with a reference wavelength 630 $\mathrm{nm}$ to avoid the interference of cell layer absorbance that block light passing through.

\section{Assessment of apoptosis by single cell gel electrophoresis (comet)}

The single cell gel electrophoresis also (comet assay) was performed as previously described [23]. In brief, HCT116 cells at a density of $1.3 \times 10^{4} / \mathrm{cm}^{2}$ were plated in 6-well cell culture plate and exposed to indicated concentrations of CAERS for three $24 \mathrm{~h}$. The cells were then harvested and resuspended in ice-cold PBS. Approximately, $1 \times 10^{4}$ cells were resuspended in $0.5 \%$ (w/v) low melting-point agarose, pipetted onto a thin layer of $1.0 \%(\mathrm{w} / \mathrm{v})$ agarose-coated slide and immersed in ice cold lysis buffer. After $4 \mathrm{~h}$ at $4^{\circ} \mathrm{C}$, the slides were subjected to electrophoresis for $30 \mathrm{~min}$, transferred to neutralization buffer and stained with ethidium bromide for $5 \mathrm{~min}$. To prevent additional DNA damage from visible light, all the steps described above were conducted under a dimmed light. Cells with comet image were analyzed using the 40X magnification objective lens and fluorescence microscope equipped with an excitation filter of 546/10 nm and a barrier filter of $590 \mathrm{~nm}$. Comets were recorded and analyzed using a Variocam (PCO, Germany) connected to a PC running Komet 4.0 image analyzer (Kinetic imaging, UK).

Assessment of apoptosis by DNA fragmentation assay (DNA Ladder Analysis).

Genomic DNA extraction and electrophoresis were performed as previously described [23]. HCT116 cells were treated with indicated concentrations for $24 \mathrm{~h}$, collected by centrifugation, and genomic DNA was extracted using the DNA Purification Kit (Thermo-USA) following manufacturer's instructions. The purified DNA was analyzed for the detection of any fragmentation by separation on $1 \%$ agarose gel.

Assessment of apoptosis by BrdU-labeled DNA fragments

Cellular DNA fragmentation ELISA assays were performed with a kit according to the manufacturer's instructions (Roche Molecular Biochemicals, Mannheim, Germany).

Assessment of apoptosis Caspase-3/7 dependent activity Caspase-3/7 activities were determined by using the Apo-ONE® Homogeneous Caspase-3/7 Assay (Promega), according to the manufacturer's instructions. Briefly, HCT 116 cells were seeded on a $96-$-well TC plate $\left(10^{4}\right.$ cells/ well) and treated with indicated concentrations of CAERS for $24 \mathrm{~h}$. Then, activities of caspase-3/7 were measured according to manufacturer's instructions. Briefly, $100 \mu \mathrm{l}$ of Apo-ONE® caspase-3/7 reagent was added to each well and the contents of the wells were mixed using a plate shaker at $400 \mathrm{rpm}$ for 12 hours. The developed fluorescence of each well was measured using micro-plate reader (BioTek Synergy HT, USA) at 485Ex, 528Em and at gain 40 , all values have been subtracted from the blank control (no cells) representing background fluorescence associated with the culture system and Apo-ONE® caspase-3/7 reagent.

Assayingthe activities of the transcription factors, Ap-1, $N F-x B$ and $N r f 2$

The ability of CAERS to alter the constitutive transcriptional activity of AP-1-dependent gene and $\mathrm{NF}-\varkappa \mathrm{B}$-dependent gene expression, were determined by luciferase reporter gene assay, according to the manufacturer's instructions. HCT116 cells $\left(4 \times 10^{4}\right.$ cells/ well) were plated in 24-well plates and transiently transfected with either a pAP1-Luc Cis-Reporter plasmid reporter construct (Agilent Technologies, USA) or PathDetect ${ }^{\circledR}$ NF-kB Cis-Reporting System (Stratagene, USA) and Cignal reporter Nrf2 (QIAGEN) containing AP- 1 or NF- $x$ B and Nrf 2 binding sites linked to the firefly luciferase reporter gene. In some experiments (indicated), HCT116 cells were co-transfected with the AP-1-Luc reporter and pNF- $x \mathrm{~B}-$ Luc reporter along with an upstream pFC-MEKK control plasmid, pFC-MEKK (Agilent Technologies,USA). For cells normalization, cells were co-transfected with $5 \mathrm{ng} /$ well of the Renilla luciferase reporter plasmid phRL-TK for 24hours.Post-transfection, cells were treated with the indicated concentrations of CAERS for $24 \mathrm{~h}$, then cells were harvested and assayed for luciferase level using the dual-luciferase reporter assay system (Promega Corp), according to the manufacturer's instructions. Reading of luciferase activity relative light units (RLU) was carried out by using micro-plate reader (BioTek Synergy HT, USA) at 640Em at gain40.

Assayingthe DNA-binding activities of NF-xB, AP-1 and Nrf-2 Proteins 
Measuring DNA-binding activities of NF- $x \mathrm{~B}, \mathrm{AP}-1$ and Nrf-2 proteins was performed according to the manufacturer's instructions. HCT116 cells were seeded in six well-plates $\left(2 \times 10^{5}\right.$ cells/well $)$, treated with different concentrations of CAERS for 24, collected and washed in PBS; then nuclear extracts were prepared, according to manufacturer procedure using NE-PER ${ }^{\circledR}$ nuclear and cytoplasmic extraction reagents (Thermo Scientific). The extracted protein was quantified using Pierce ${ }^{\mathrm{TM}}$ BCA Protein Assay Kit (Thermo Scientific). DNA-binding activities of the NF- $x$ B, AP-1, and Nrf2 were assessed using the transcription factor assay kit, TransAm ${ }^{\circledR}$ (Active Motif, USA). The assays were carried by incubating overnight $10 \mu \mathrm{g}$ of nuclear protein samples at $4^{\circ} \mathrm{C}$, in a 96-well plate coated with a binding site for either NF- $x \mathrm{~B}$, AP-1, or Nrf2, to which activated NF- $x$ B/p65, Ap-1/cFos, Ap-1/c-Jun or Nrf2 in nuclear extracts specifically binds. The plates were extensively washed according to manufacturer's instructions and incubated with primary antibodies raised against each of NF- $x \mathrm{~B} / \mathrm{p} 65$, Ap-1/cFos, Ap-1/c-Jun or Nrf2. Then, the plates were washed and incubated with secondary antibody, horseradish peroxidase (HRP)-conjugated antibody; specific binding was estimated colorimetrically at $450 \mathrm{~nm}$. Values were normalized to the background readings.

\section{$R N A$ extraction and reverse transcriptase-PCR}

RNA extraction and quantitative reverse transcription PCR was carried out as detailed previously (Elkady et al., 2015). Briefly, cells were plated and treated with indicated concentrations as aforementioned. 24-post treatment, both floating and adherent cells were collected, and pelleted by centrifugation at $700 \mathrm{~g}$ for $5 \mathrm{~min}$. total ribonucleic acid (RNA) was extracted, reverse transcribed and amplified by polymerase chain reaction (PCR) using QIAamp® RNA Blood Mini Kits (QIAGEN) following manufacturer's instructions. Expression of tested genes was examined by PCR method using gene-specific primers.

\section{Western blot analysis}

The total cell lysates and Western blot were carried out as reported (Elkady et al., 2015). Briefly, after treatment, the cells were collected, washed with cold PBS and lysed. Then, aliquots of the total cell lysates containing the same quantity of proteins were boiled for $5 \mathrm{~min}$ in sodium dodecyl sulfate polyacrylamide gel electrophoresis (SDS-PAGE) sample buffer containing 5\% $\beta$-mercaptoethanol, electrophoresed on $10 \%$ SDS-PAGE and transferred to PVDF membranes. The membranes were then incubated with primary antibody against tested proteins (aprox.1:500), followed by incubation with a secondary horseradish peroxidase-conjugated antibody (aprox.1:1000). The first and second antibodies were purchased from Santa Cruze. The signals were visualized with enhanced chemiluminescent (ECL) substrates. Equal loading of proteins was confirmed by stripping the blots and re-probing with $\beta$-actin.

\section{Statistical analysis}

All experiments were repeated two times independently and in triplicate. The results were presented as mean \pm standard deviation (SD) for continuous variables. Differences between samples were analyzed with by oneway analysis of variance (ANOVA).

\section{Results}

HPLC-MS Analysis of Rhazya Stricta Strongly Basic Alkaloids

High-performance liquid chromatograph-mass spectroscopy of Rhazya stricta alkaloid extract on HPLC /LCQ Fleet-Thermo Scientific. Analysis was carried out as described in Materials and Methods section. Two of the peaks have been identified as rhazinilam and sewarine and the major peaks of the extract are indicated in Tables 1-3 and Figure 1. The nature of the remaining compounds is in the process of being identified.

\section{The anti-proliferative effects s of CAERS:}

HCT116 cells were cultured in the presence of increasing concentrations $(25,50,75,100,125$ and $150 \mu \mathrm{g} / \mathrm{ml}$ ) of CAERS and the number of cells was determined after 24, 48 and 72 husing tetrazolium salt WST-1 proliferation assay kit. As shown in Figure 2A, CAERS consistently exhibited does- and time-dependent anti-proliferative effects on the cell viability. The $\mathrm{IC}_{50}$ values (the concentration of test compound that inhibits $50 \%$ of the cell growth) observed after 24,48 and $72 \mathrm{~h}$ of

Table 1. Identification of Strong Basic Alkaloids Present in Fractions from $R$. stricta

\begin{tabular}{ccccc}
\hline Compound & $\begin{array}{c}\mathrm{tR} \\
(\mathrm{min})\end{array}$ & $\begin{array}{c}\mathrm{m} / \mathrm{z} \\
{[\mathrm{M}]+}\end{array}$ & $\begin{array}{c}\text { Relative } \\
\text { Abundance }\end{array}$ & compound \\
\hline 1 & 6.99 & 228.82 & $<95$ & \\
2 & 6.99 & 252.78 & $<45$ & Rhazinilam \\
3 & 8.61 & 294.03 & 100 & \\
4 & 9.71 & 249.25 & 100 & \\
5 & 10.37 & 297.3 & 100 & \\
6 & 11.19 & 311.31 & 100 & \\
7 & 13.11 & 325.40 & 100 & \\
8 & 13.11 & 339.31 & 100 & Sewarine \\
\hline
\end{tabular}

$\mathrm{tR}$ :retention time

Table 2. Conditions of HPLC-MS Analysis

\begin{tabular}{ll}
\hline Instrument Information & \multicolumn{1}{c}{$\begin{array}{c}\text { HPLC /LCQ Fleet Thermo } \\
\text { Scientific }\end{array}$} \\
\hline $\begin{array}{l}\text { Pump } \\
\text { Outsampler }\end{array}$ & $\begin{array}{l}\text { ACCELA } \\
\text { ACCELA } \\
\text { A: H } 20\end{array}$ \\
Mobile phase: & $\begin{array}{l}\text { B: Acetonitrile } \\
\text { Gradient program }(90: 10 \text { to }\end{array}$ \\
& $0: 100)$ \\
Analysis technique & HPLC-MS (Ion trap) \\
Injection volume & $2 \mu 1$ \\
Solubility & Methanol: Chloroform $(1: 1)$ \\
Flow rate & $550 \mu 1 /$ min \\
Column & Hyperisl Gold $(150 * 2.1 \mathrm{~mm}, 3 \mu \mathrm{m})$ \\
Run time & 15 min \\
Polarity & Positive mode \\
Mass range & $100-500$
\end{tabular}


Table 3. Identification of Strong Basic Alkaloids Present in Fractions from $\boldsymbol{R}$. stricta

\begin{tabular}{c|c|c|c|c}
\hline Compound & $\begin{array}{c}\mathrm{tR} \\
(\mathrm{min})\end{array}$ & $\begin{array}{c}\mathrm{m} / \mathrm{z} \\
{[\mathrm{M}]+}\end{array}$ & $\begin{array}{c}\text { Relative } \\
\text { Abundance }\end{array}$ & compound \\
\hline 1 & 6.99 & 228.82 & $<95$ & \\
2 & 6.99 & 252.78 & $<45$ & Rhazinilam \\
3 & 8.61 & 294.03 & 100 & \\
4 & 9.71 & 249.25 & 100 & \\
5 & 10.37 & 297.3 & 100 & \\
6 & 11.19 & 311.31 & 100 & \\
7 & 13.11 & 325.4 & 100 & \\
8 & 13.11 & 339.31 & 100 & Sewarine \\
\hline
\end{tabular}

$\mathrm{tR}$ :retention time

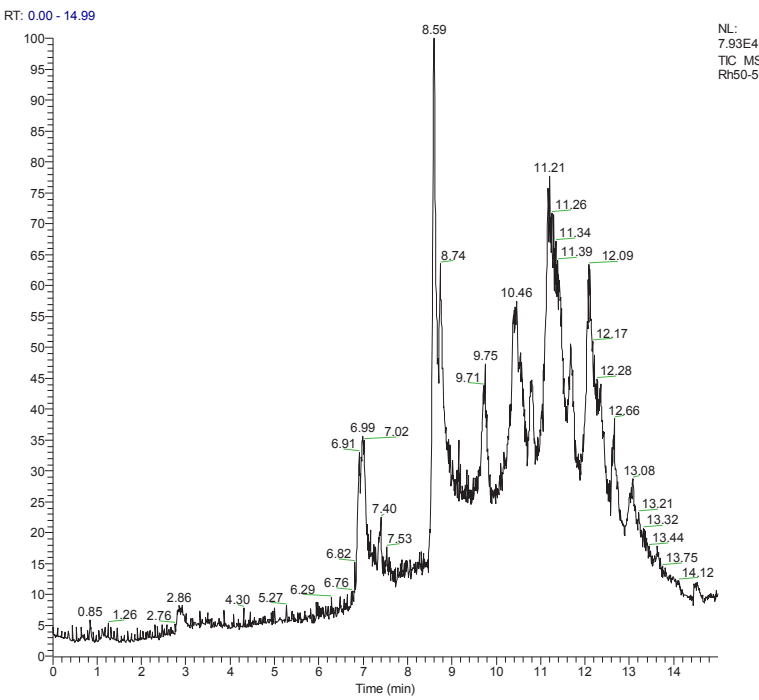

Figure 1. HPLC-ESI-MS-Total Ion Current (TIC) Chromatogram at Positive Mode for the Strong Basic Alkaloids Extract of $R$. stricta

treatments were 75,60 and $45 \mu \mathrm{g} / \mathrm{ml}$, respectively.

To find out whether the anti-proliferative potentiality of CAERS is unique to HCT116 cells, the above experiments were repeated using human breast and liver cancer cell lines, MCF-7 and HepG2, respectively, as models. We observed similar results (Figure 2B and C). Collectively, these results indicated that the CAERS markedly inhibited growth of the human colon HCT116 cells.

\section{CAERS Inhibits DNA Synthesis in HCT116 Cells}

It is documented that most phytochemical agents mediate their chemopreventive potentialities via inhibition of cell proliferation (Khan et al., 2007). To determine whether the reduction of cell number in aforementioned experiments is due to inhibition of proliferation, we determined the rates of DNA synthesis. HCT116 cells were treated with $25,50,75$ and $100 \mu \mathrm{g} / \mathrm{ml}$ of CAERS for $24 \mathrm{~h}$ and DNA synthesis was assessed. We found that increased appearance of DNA fragments in treated cells, indicating that CAERS treatments caused suppression of DNA synthesis (Figure 3).

CAERS Treatments Induce Apoptosis in HCT116 Cells Review Figureures

HTC116 cells were treated for 24 hours with CAERS
Harmal Extract Induces Apoptosis in Colon Cancer Cells
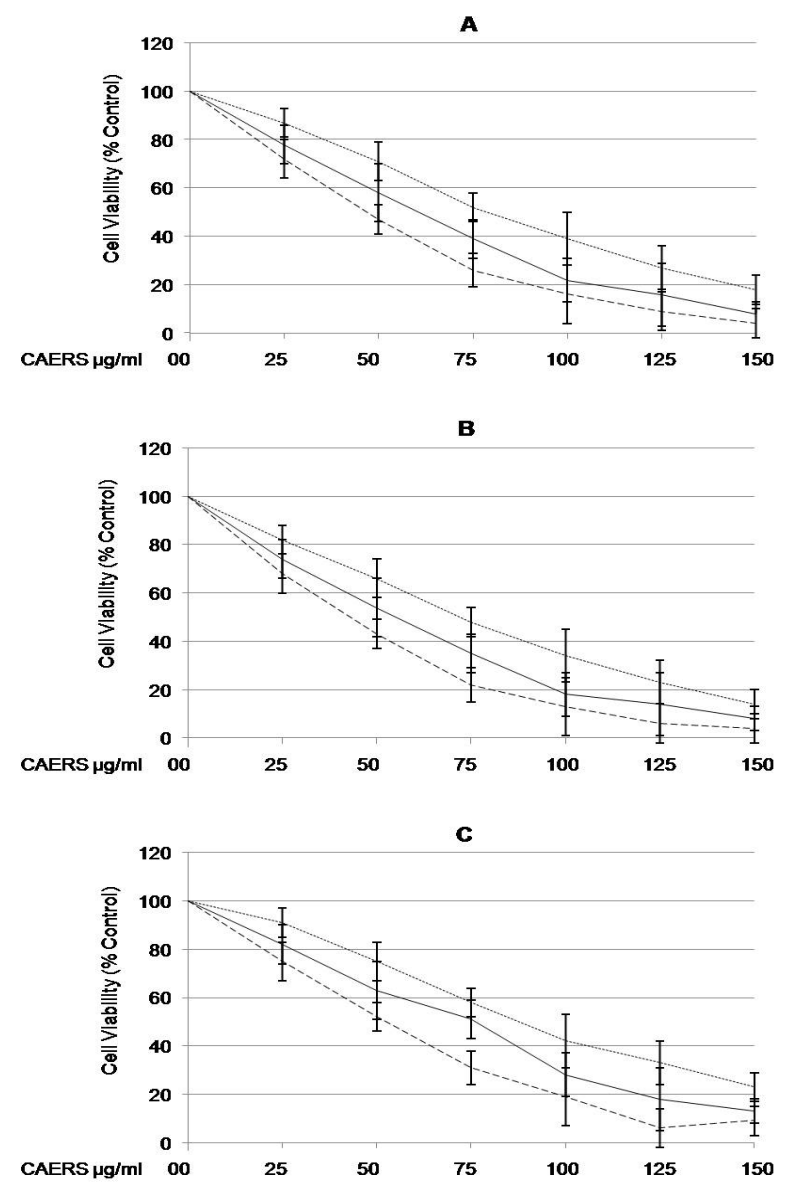

Figure 2. Effect of CAERS on the Proliferation of Cancer Cell Lines. The HCT116 (A), MCF-7 (B) and HepG2 (C) cells were incubated with the indicated concentrations of CAERS for 24 (dotted), 48 (solid) and 72 (dashed) lines. The inhibition of cell proliferation was assessed by the tetrazolium salt WST-1 kit as detailed in section "Materials and Methods". The experiments were repeated five times in triplicates, and cell viabilities at each dose of the CAERS were expressed in terms of percent of control and reported as the mean \pm SD.

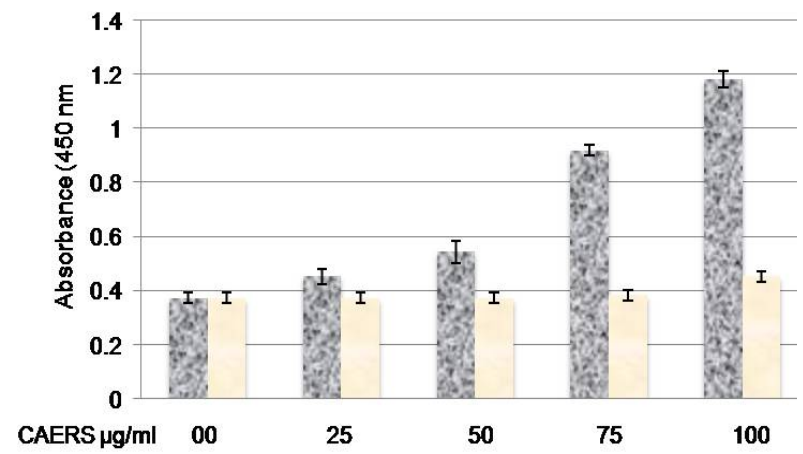

Figure 3. CAERS Treatment Induced Morphological Features of Apoptosis in HCT116 Cells. The cells were treated with the indicated concentrations of CAERS for $24 \mathrm{~h}$. Depicted results are representative for independent experiments with almost identical observations. (A) The Microphotographs were taken directly from culture plates using a phase microscope Row I, 10x; Row II, 20x; Row III, 40x. (B) Hoechst 33342 stain showing CAERS induced chromatin condensation and nuclei fragmentation (arrows) in HCT116 cells treated CAERS. Row IV, 20x; Row V, 40x 
and then examined directly under inverted microscope. As seen in Figure 4A, untreated HCT116 cells appeared adherent and assumed a normal epithelial morphology forming confluent monolayer. In contrast, cells treated with CAERS appeared much more readily detached and displayed rounded-up, balloon-like shape. Next, HTC116 cells were treated for $24 \mathrm{~h}$ with CAERS, stained with Hoechst 33342 stain and investigated under fluorescent microscope. As shown in Figure 4B, control cells appeared with a homogenous morphology containing evenly stained nuclei. On the other hand, treated cells exhibited features of cells apoptotic cell death including chromatin condensation and formation of apoptotic bodies.

\section{CAERS Treatments Induce DNA Damage}

To further demonstrate the apoptotic effect of CAERS, we also subjected the HCT 116 cells after $24 \mathrm{~h}$ of treatment with the alkaloid to single cell gel electrophoresis (comet test). The length of the comet tail and the comet tail moment (generated automatically by the image analyzer system) were measured in 50 cells for each treatment and for each group means \pm SD were calculated. The DNA damaging effect of CAERS in HCT116 is given in Figure 5. There was a significant difference between the basal value of the untreated cells and the cells treated with CAERS. In the treated cells the extent of DNA damage was increasing with the increasing concentrations of CAERS. The increase was in the number of cells which exhibited comet and the increase in the comet tail moment (tail length $\mathrm{x}$ amount of DNA in the tail). The percentage of cells with comet in the CAERS-treated cells reached up to $95 \%$ at a dose of $125 \mu \mathrm{g} / \mathrm{ml}$, compare with the control which showed comet in $0-5 \%$ of the cells (Table 4 ). Also the comet tail moment increased from 0.03 in the control to 84 at a dose of $125 \mu \mathrm{g} / \mathrm{ml}$.

It has been demonstrated that necrotic/genotoxic agents can induce comet tail; nonetheless, the comet image generated by an apoptosis-inducing agents is different from that obtained with a cell treated with a necrotic/genotoxic agents. The comet formed by apoptotic agents has a characteristic image, called pear-shaped or teardrop (Wilkins et al., 2002). Therefore, we aimed at characterizing and analyzing the different features of comet induced by CAERS in HCT116 cells to see whether this comet is due to apoptotic or necrotic effect. To compare these two types of damaging potentials, we compared the CAERS induced comet with the comet induced by $\mathrm{H}_{2} \mathrm{O}_{2}$ and Benzo(a)pyrene, both are potent DNA damage-inducing agents. They cause DNA strand breaks and does not induce comet characteristic to apoptosis in the comet assay (Kumar et al., 2012; Kundu, 2005). Figure 5 shows comets, obtained from HCT116 cells treated with CAERS. It is easily seen that these comets are quite different in comparison with $\mathrm{H} 2 \mathrm{O} 2$ and Benzo(a)pyrene -obtained ones. The comets obtained by CAERS showed a pear-shape and displayed a typical stained clusters of DNA (apoptotic bodies) in the comet head; this clustered DNA is indicative of apoptotic cells, a feature which is not seen in the genotoxic chemicals, $\mathrm{H}_{2} \mathrm{O}_{2}$ and Benzo(a)pyrene.

Fragmentation of DNA at the inter-nucleosomal linker

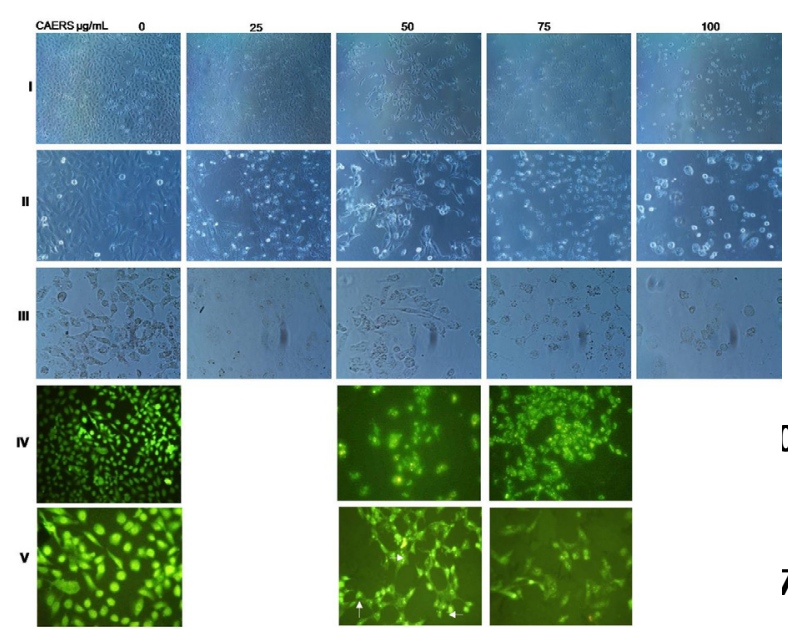

Figure 4. CAERS Treatment Induced Morphological Features of Apoptosis in HCT116 Cells. The cells were treated with the indicated concentrations of CAERS for $24 \mathrm{~h}$. Depicted results are representative for independent experiments with almost identical observations. (A) The Microphotographs were taken directly from culture plates using a phase microscope Row I, 10x; Row II, 20x; Row III, 40x. (B) Hoechst 33342 stain showing CAERS induced chromatin condensation and nuclei fragmentation (arrows) in HCT116 cells treated CAERS. Row IV, 20x; Row V, 40x
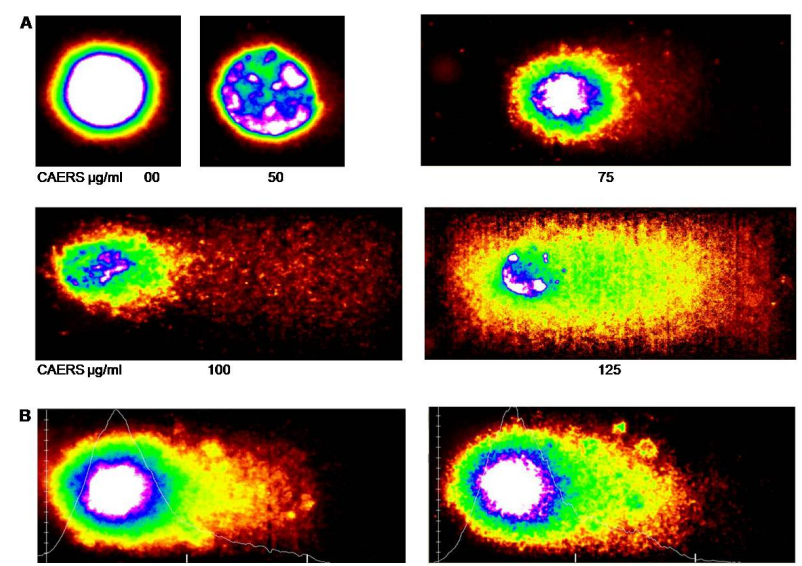

Figure 5. CAERS Treatments Induce DNA Damage in HCT116 Cells. (A) The cells were treated with the indicated concentration of CAERS for $24 \mathrm{~h}$, harvested and assayed as detailed in Materials and Methods. Notice, at $100 \mu \mathrm{g} / \mathrm{mL}$ CAERS, cells comet tail appeared fan-like shape, which is a typical characteristic of apoptotic cell death. (B) Necrotic effect of $\mathrm{H}_{2} \mathrm{O}_{2}$ and Benzo(a)pyrene on HCT116 cells. The cells were treated with $10 \mu \mathrm{M} / \mathrm{ml}$ of $\mathrm{H} 2 \mathrm{O} 2$ (left panel) or $10 \mu \mathrm{M} / \mathrm{ml}$ of Benzo(a)pyrene, then subjected to single cell gel electrophoresis under alkaline conditions as detailed in Materials and Methods

regions is an irreversible event in apoptotic cascades and has been observed in cells undergoing apoptosis induced by a variety of agents and is widely used as biochemical markers of apoptosis (Nagata, 2000). Therefore, we examined whether CAERS might induce DNA fragmentation in HCT116 cells. As seen in Figure 6, CAERS induced oligonucleosomal DNA fragmentation, in a dose-dependent manner. The Figure shows too, at the highest dose of CAERS treatment $(125 \mu \mathrm{g} / \mathrm{ml})$, all DNA was damaged.

Effects of CAERS on Caspase-3/7 activity in HCT116 cell Both extrinsic and intrinsic apoptotic pathways 
Table 4. Effect of CAERS on HCT116 cells. The cells were treated with the CAERS for $24 \mathrm{~h}$, then subjected to single cell gel electrophoresis under alkaline conditions and analyzed by comet analysis system EDRI technology. Comet tail moment is generated automatically by the image analyzer system and the mean for 50 comet tail were calculated

\begin{tabular}{ccc}
\hline CAERS & Comet Cells (\%) & $\begin{array}{c}\text { Comet Tail } \\
\text { Moment }\end{array}$ \\
\hline Control & $0-5$ & 030. \\
$25 \mu \mathrm{g} / \mathrm{ml}$ & $20 \pm 4$ & $5 \pm 4$ \\
$50 \mu \mathrm{g} / \mathrm{ml}$ & $35 \pm 5$ & $12 \pm 5$ \\
$75 \mu \mathrm{g} / \mathrm{ml}$ & $66 \pm 3$ & $33 \pm 4$ \\
$100 \mu \mathrm{g} / \mathrm{ml}$ & $84 \pm 6$ & $72 \pm 7$ \\
$125 \mu \mathrm{g} / \mathrm{ml}$ & $95 \pm 3$ & $84 \pm 7$ \\
\hline
\end{tabular}

eventually converge down at a common pathway, or the execution phase of apoptosis, activation of caspase-3/7 (Wong, 2011). Therefore, the involvement of proapoptotic caspase3/7 in CAERS-induced HCT116 cell apoptosis was assessed. HCT116 cells were incubated for 24 hours with increasing concentrations of CAERS for $24 \mathrm{~h}$ and activity of caspase-3/7 was assayed by Apo-ONEß Homogeneous Caspase-3/7 assay kit. The findings of these experiments showed that treatment of cells with CAERS dose-dependently increased caspase-3/7 activity (Figure 7). The highest dose of CAERS $(100 \mu \mathrm{g} / \mathrm{ml})$ induced the activity of the caspase as high as three-fold of its basal level. These results further suggested that CAERS induced apoptotic cell death and that death is associated with the caspase- $3 / 7$ activation.

\section{CAERS Treatments Suppress Activities of NF-xB and} AP-1 Proteins

Constitutive activation of NF- $x \mathrm{~B}$ activity has been demonstrated in CRC and sustained activation of NF$\varkappa \mathrm{B}$ is closely correlated with resistance to the apoptosis induced by various chemotherapeutic agents in colorectal cancer cells (Ban et al., 2007). Thereby, we investigated effect of CAERS on activity of NF- $x$ B. Results in Figure $8 \mathrm{~A}$ showed that CAERS inhibited basal transcriptional activity of reporter gene driven by NF- $x \mathrm{~B}$-response elements. Since NF- $x$ B can be stimulated by MAPK kinase pathway, we transfected cells with the NF$x \mathrm{~B}$ reporter construct along with an upstream kinase (MEKK) expression construct (pFC-MEKK). Once more, we got transcriptional inhibition after treatment cells with CAERS (Figure 7B), which indicate that CAERS treatments have a potentiality to abolish constitutive and activated transcriptional activities of NF- $x \mathrm{~B}$ in HCT116 cells. To elucidate the mechanism underlying suppression of NF- $x \mathrm{~B}$ activity by CAERS treatments, we investigated of the effect of CAERS on the DNA-binding activity of $\mathrm{NF}-x \mathrm{~B}$. The cells were treated with CAERS different concentrations, and we assessed the DNA-binding activity of NF- $x \mathrm{~B}$ nuclear subunit, p65,bound to the consensus $\mathrm{NF}-x \mathrm{~B}$ response element. The findings in Figure $7 \mathrm{C}$ demonstrate that CAERS, dose-dependently, abrogated DNA-binding activity of p65 subunit. So we concluded that abrogating transcriptional activity of NF- $x \mathrm{~B}$ by CAERS is due to inhibition of binding p65 subunit to DNA.
Harmal Extract Induces Apoptosis in Colon Cancer Cells

Accumulated studies confirm that various agents that activate NF- $x$ B also activate AP-1 protein (Gopalakrishnan and Kong, 2008) and activation of AP-1 is involved in CRC carcinogenesis (Vaiopoulos et al., 2010), therefore, we tested whether CAERS affects transcriptional and DNA-binding activities of AP-1. As shown in Figure 8, CAERS treatments inhibited basal (A) and activated (B)

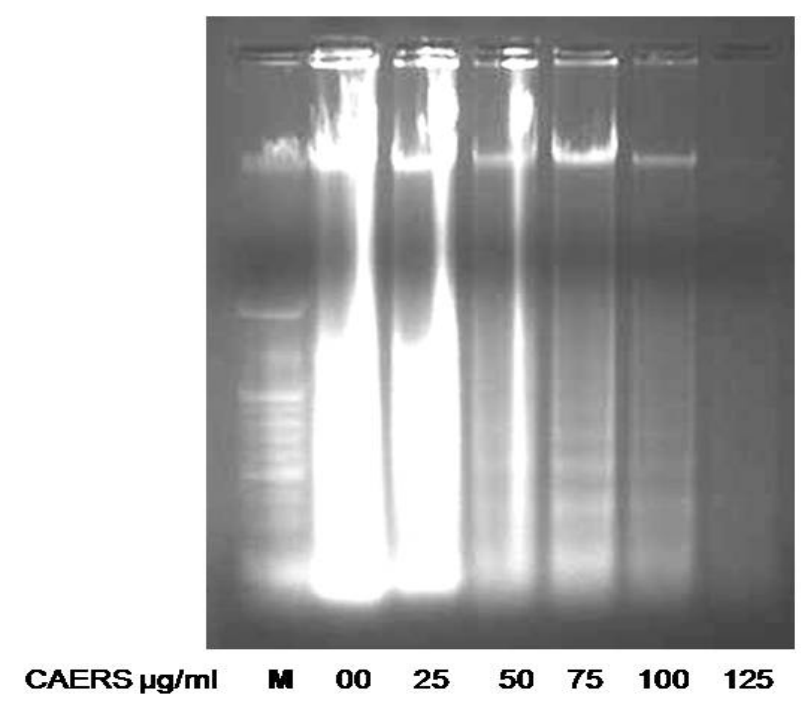

Figure 6.CAERS Treatments Induced Oligonucleosomal Degradation of DNA in HCT116 Cells. The cells were treated with indicated doses of CAERS for $24 \mathrm{~h}$, then genomic DNA was extracted and subjected to agarose gel electrophoresis; "M" DNA marker ladder

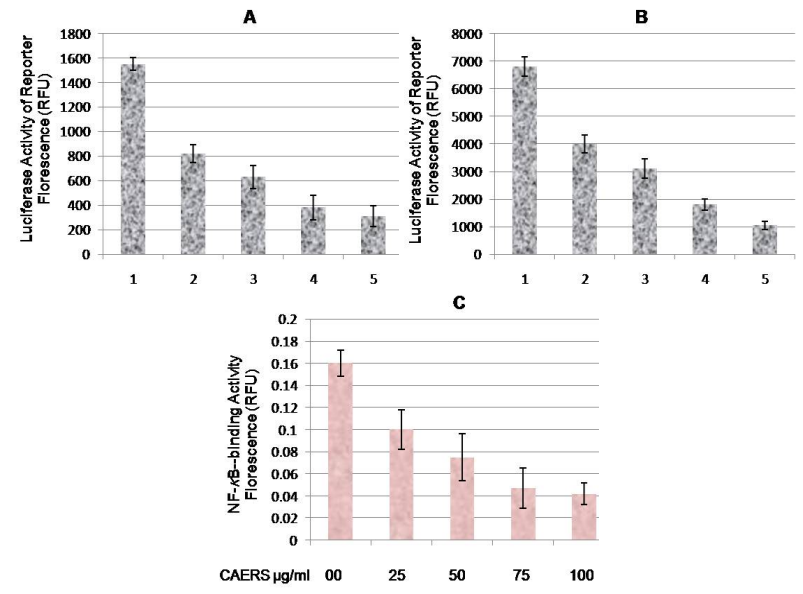

Figure 7. CAERS Inhibits Transcriptional and DNA-Binding Activities of NF- $\boldsymbol{x B}$. HCT116 cells were transfected with a plasmid reporter construct (pNF- $x \mathrm{~B}-\mathrm{Luc}$ ) containing NF- $x \mathrm{~B}$ binding sites linked to the firefly luciferase reporter gene alone (A), or along with an upstream kinase MEKK expression construct (pFC-MEKK) (B). To normalize for transfection efficiencies in all experiments, cells were also cotransfected with $5 \mathrm{ng} /$ well of the Renilla luciferase reporter plasmid. 24-h post-transfection, cells were treated with indicated concentrations of CAERS for $24 \mathrm{~h}$, then cells were harvested and assayed for luciferase level as has been detailed in Materials and Methods. Firefly activities were corrected for Renilla activities and expressed as adjusted RLU. (C) Cells were treated with the indicated concentrations of CAERS for $24 \mathrm{~h}$; then nuclear extracts were prepared and DNA-binding activity of NF- $x \mathrm{~B} /$ p65 was performed on $10 \mu \mathrm{g}$ of nuclear extract using TransAm Active Transcription Factor Assay Kit as detailed in Materials and Methods 

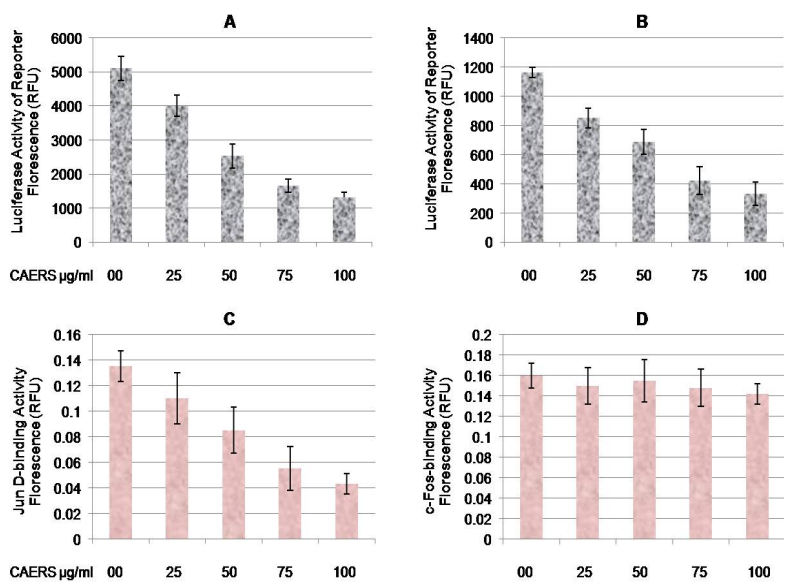

Figure 8. CAERS Inhibits Transcriptional and DNA-

Binding Activities of AP-1 Proteins. HCT116 cells were transfected with a plasmid reporter construct (pAP-1-Luc) containing Ap-1 binding sites linked to the firefly luciferase reporter gene alone (A), or along with an upstream kinase MEKK expression construct (pFC-MEKK) (B). To normalize for transfection efficiencies in all experiments, cells were also cotransfected with $5 \mathrm{ng} /$ well of the Renilla luciferase reporter plasmid. 24-h post-transfection, cells were treated with indicated concentrations of CAERS for $24 \mathrm{~h}$, then cells were harvested and assayed for luciferase level as has been detailed in Materials and Methods. Firefly activities were corrected for Renilla activities and expressed as adjusted RLU. (C) Cells were treated with the indicated concentrations of CAERS for $24 \mathrm{~h}$; then nuclear extracts were prepared and DNA-binding activities of Jun D (C) and c-Fos (D) were performed on $10 \mu \mathrm{g}$ of nuclear extract using TransAm Active Transcription Factor Assay Kit as detailed in Materials and Methods

transcription of a reporter gene driven by AP-1-response elements. Furthermore, CAERS treatments inhibited DNA-binding activity of AP-1 subunit, c-Fos (C) and did not alter that of Jun D (D).

\section{CAERS Treatments Promote Activity of Nrf2}

It has been shown that many bioactive agents are known to exert their chemopreventive roles through induction of Nrf2, a master regulator of genes controlling expression of antioxidant/phase II detoxifying enzymes (Lee and Jeffrey, 2004). So we investigated whether CAERS have an ability to stimulate transcription activity of a reporter gene driven by Nrf2-response element. When the HCT116 cells transfected with a reporter construct driven by pNrf2-response elements, results showed that CAERS enhanced, in a dose-dependent manner, the constitutive transcriptional activity of the reporter (Figure 9A). Next, we prepared nuclear extracts from cells treated with increasing concentration of CAERS and we assessed amount of Nrf2 bound to the consensus ARE-response element. Results showed that CAERS enhance DNAbinding activity of Nrf2 (Figure 9B).

Next, we treated HCT116 cells with increasing doses of CAERS, then cells were harvested and expression levels of the Nrf2 down-stream target genes including hemeoxygenase (HO-1), $\mathrm{NAD}(\mathrm{P}) \mathrm{H}$ quinine oxidoreductase 1 (NQO1) and UDP-glucuronyltransferase (UGT1A1) genes were assayed by quantitative reverse transcription PCR. The data displayed in Figure 9C

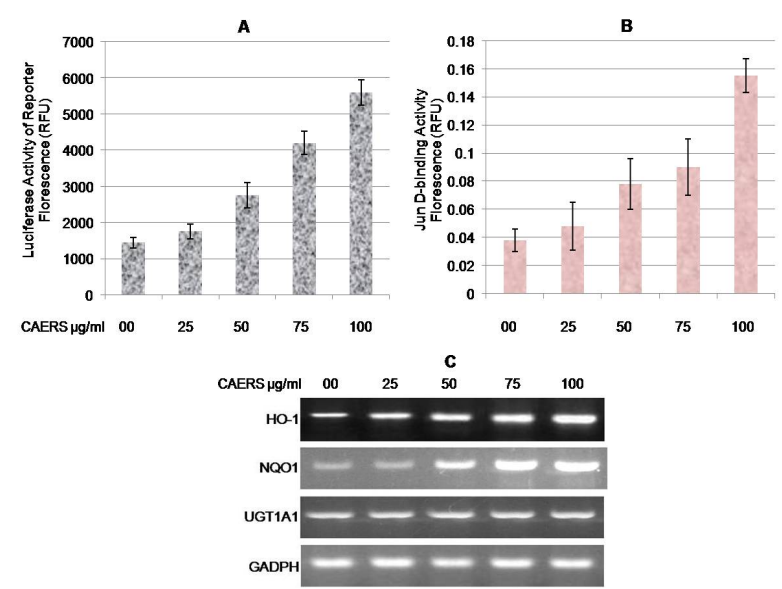

Figure 9. CAERS Enhances Constitutive Transcriptional and DNA-Binding Activities of Nrf2 Protein. (A) HCT116 cells were transfected with Nrf-2 luciferase reporter construct; 24 -h post-transfection, cells were treated with indicated concentrations of CAERS for $24 \mathrm{~h}$, then cells were harvested and assayed for luciferase level as has been detailed in Materials and Methods. Firefly activities were corrected for Renilla activities and expressed as adjusted RLU. (B)Effect of CAERS on DNA-binding activity of Nrf2. Cells were treated with the indicated concentrations of CAERS for $24 \mathrm{~h}$; then nuclear extracts were prepared and DNA-binding activity of Nrf2 was performed on $10 \mu \mathrm{g}$ of nuclear extract using TransAM active transcription factor assay kit. (C) CAERS treatments up-regulated the expression levels of the displayed gene products. After CAERS treatments total RNA was isolated, reverse-transcribed, and subjected to PCR with gene-specific primers. The PCR products of the genes were then subjected to electrophoresis in $1 \%$ agarose gels and visualized by staining with ethidium bromide. GAPDH was used as the internal control.

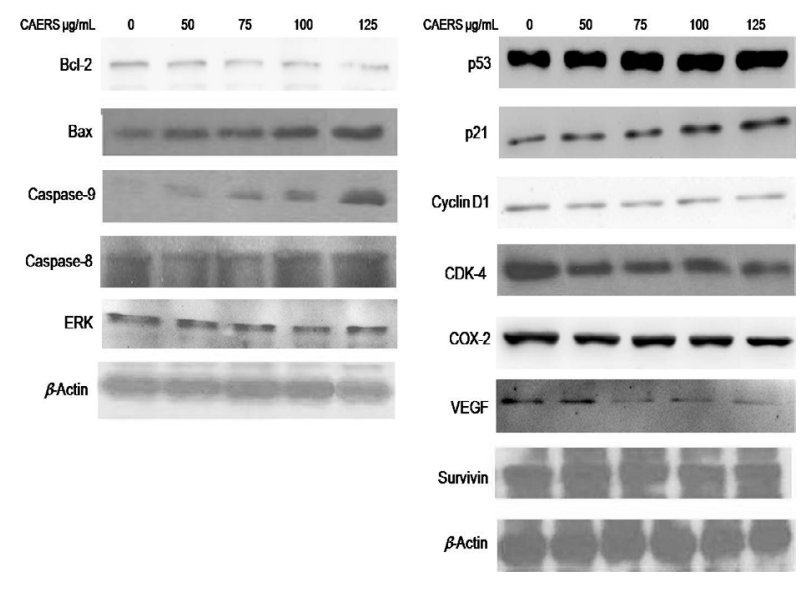

Figure 10. CAERS Modulates Expression Levels of Key Cellular Protein Involved in CRC Carcinogenesis. The HCT116 ells were incubated with the indicated concentrations of the CAERS for $24 \mathrm{~h}$, then total cell lysates were prepared and subjected for Western analyses using antibodies raised against displayed proteins. The experiments were repeated several times and typical results from independent experiments are shown

indicate that CAERS dose-dependently markedly induced expression levels of HO-1and NQO1; it also induced, albeit to a less extent, expression level of UGT1A1. We concluded from these experiments that activation of detoxifying/antioxidant enzyme system by CAERS may contribute to its potentiality to act as a chemo-preventive agent. 
Effect of CAERS on the Expression of Cell Cycle and Apoptosis Related Proteins

To investigate the possible mechanism underlying the induction of apoptosis by CAERS, we examined the expression of Bcl-2 and Bax in HCT-116 cells after treatment with CAERS. The expression of Bcl-2 decreased markedly, while the expression of Bax increased in a time-dependent manner (Figure 10). We then examined the activation of caspase cascade in HCT116 cells; in response to CAERS, the expressions of the active forms of caspase- 9 and caspase- 3 increased in a dose-dependent manner. These results demonstrated that CAERS induced apoptosis in HCT116 cells through alteration of Bcl-2/Bax ratio and activation of caspases.

The ERK MAPK cascade is an up-stream effectorof $\mathrm{NF}-\varkappa \mathrm{B}$ and AP-1 and activation of this cascade plays an important role in the pathogenesis and progression of human CRC (Fang and Richardson, 2005). To investigate effect of CAERS on activity of ERK MAPK, we analyzed the phosphorylation of ERK by Western blot. As shown in Figureure10, treatment with increasing doses of CAERS inhibited ERK phosphorylation. Since ERK cascade is mostly associated with cellular survival and proliferation brought on by mitogenic inputs (Fang and Richardson, 2005). These results indicate that the inhibition of ERK by CAERS could be responsible, at least in part, for the anti-proliferative potentiality of CAERS in HCT116 cells.

To further understand the mechanism of CAERS induced growth-suppression and apoptosis in HCT116 cells, the protein expressions of several cell cycle and apoptosis related proteins in HCT116 cells with CAERS was examined with Western blot analysis. As displayed in Figureure 10, Western blot results showed downregulation of the anti-apoptotic proteins, Bcl-2, Survivin and enhanced expression of the pro-apoptotic protein, Bax. The treatment led too up-regulation of tumor suppressor protein $\mathrm{p} 53$, its down-stream effector, p21. On the other hand, the expression levels of the cell cycle regulators, cyclin D1 and CDK4 are decreased. CAERS treatments decreased also level of cyclooxygenase-2 (COX-2) and VEGF.

\section{Discussion}

CRC is a major cause of cancer-related death worldwide ((Levin et al., 2008). Therefore, it is necessary to develop a new anti-cancer agent for the management of this disease. To this end, medicinal plants can provide mankind with novel anti-cancer agents. The present study aimed to examine the ability of crude alkaloid extract isolated from the medicinal herbR. stricta to suppress proliferation of CRC cell line HCT116 and to elucidate the molecular mechanisms underlying growth suppression. The significance of utilizing crude extract, rather than isolated compounds, is that most studies have reported, in some cases, herbal extracts show more potency than the purified components due to the additive and/or synergistic protective effects of the involved bioactive components (Seeram et al., 2004, 2005). Consistent with these studies, we observed, in our previous studies, an efficient inhibition of cell growth in wide range of cell lines after treatment with CAERS (Elkady et al., 2013; 2014). We speculated that the significant growth-suppression, the observed apoptotic events and the down-regulation of the signalling targets, including NF- $x \mathrm{~B}$ and AP-1, in the HCT116 cells, are likely attributed to the synergistic/additive effects of the active constituents present in CAERS.

The hallmarks of cancer include tumor cell proliferation and survival (Hanahan and Weinberg, 2011). In this study we found that the CAERS has strong dose- and timedependent anti-proliferative activity on HCT116 cells in culture. These results strongly suggest that at least some of the active components of this extract can be exploited for chemoprevention of cancer cell growth. More importantly, CAERS retained its growth-suppression potentiality in the contexts of other cancer cell lines, such as breast (MCF-7) and liver (HepG2) cancer cells. Since HCT116, MCF-7 and HepG2 cells are different cell lines derived from different tissues, it is reasonable to suggest that CAERS has a general function in suppressing cancerous cell growth and it may act through multiple pathways in these three cell lines. Since a crude alkaloid extract was used in this study, it is not possible to attribute the reported effects to specific ingredient. In addition, it cannot be ruled out that the overall observed effects were contributed by the interactions between the various compounds in the extract. Therefore, we are engaged in separation, purification and bio-assaying the purified ingredients of CAERS to disclose the true nature and extent of the active ingredient(s) for anti-cancer effects observed in vitro.

Inhibition of cell proliferation and induction of apoptotic cell death are two major mechanisms by which chemotherapeutic agents kill cancer cells (Khan et al., 2007). Coherent to this notion, the cellular and biochemical assays in the present study indicated that the proliferation inhibitory activity of CAERS was related to the induction of apoptosis. This is because the CAERS-treated HCT116 cells exhibited typically morphological features of apoptosis, such as a loss of cell viability, cell shrinkage, irregularity in cellular shape, and cellular detachment. In addition, Hoechst stain images revealed occurrence of nuclear condensation, DNA fragmentation, and apoptotic bodies in CAERS-treated HCT116 cultures. A further proof demonstrating apoptotic potential of CAERS was concluded from the results showing the degradation of DNA into oligo-nucleosomal fragments and formation of comet tail in cells treated with CAERS. Fragmentation of cellular DNA into oligo-onucleosomal fragments of multiples of 180 base pairs has been observed in cells undergoing apoptosis and is widely used as biochemical markers of apoptosis (Nagata, 2000). In addition, comet assay (or single-cell electrophoresis) can detect various forms of DNA strand breakage(dependent on the $\mathrm{pH}$ of electrophoresis) and is generally accepted as specific for cell apoptosis (Yasuhara et al., 2003). Collectively, these morphological and biochemical findings demonstrate that the cytotoxic effect observed in response to the CAERS treatment is associated with the induction of apoptosis in the HCT116 cells.

A growing list of studies confirms that most anticancer agents either directly induce DNA damage or indirectly induce secondary stress-responsive signaling pathways 
to trigger apoptosis by activation of the mitochondrial apoptotic pathway (Khan et al., 2007). The key element in this pathway is the efflux of cytochrome $\mathrm{c}$ from the mitochondria to the cytosol. Once cytochrome $\mathrm{c}$ is released into the cytosol, it activates, together with Apaf-1, caspase-9, and the latter then activates caspase-3/7 (Wong, 2011). Activation of caspase-3/7is a characteristic marker of the apoptosis and plays the central role in the initiation the execution phase of apoptosis. It triggers activation of executioner caspases and other key enzymes that undertake DNA fragmentation and cleavage of cellular proteins (Wong, 2011). The release of cytochrome $\mathrm{c}$ from mitochondria, however, is tightly regulated bya variety of factors. Among these factors, Bcl-2 protein family, including anti-apoptotic members (such as Bcl-2) and pro-apoptotic members (such as Bax), plays a pivotal role (Reed, 2000). Accordingly, the ratio of anti-apoptotic $\mathrm{Bcl}-2$ to pro-apoptotic Bax protein determines, at least in part, the susceptibility of cell to various apoptotic stimuli, and is used as a predictive marker for therapeutic response to therapy (Wong, 2011). In appropriately high levels of $\mathrm{Bcl}-2$ expression have been found in in more than half of all human tumors (Reed, 1995) including CRC (Violette et al., 2002). The findings herein demonstrate that in response to CAERS treatment, HCT116 cells exhibited activation of caspase-3/7 and marked decrease in the expression level $\mathrm{Bcl}-2$, which was associated with concomitant increase in Bax expression. These observations suggest that CAERS treatment activated one of the key executioners of apoptosis (caspase-3/7) and altered Bax/Bcl-2 ratio in favor of apoptosis induction. Therefore, CAERS has a potentiality to trigger apoptotic cascade and could be an ideal chemo-preventive or therapeutic agent for CRC.

Although a bewildering variety of mechanisms underlie carcinogenesis, the great majority of currently known oncoproteins can be assigned to a limited number of pathways or at least be demonstrated to act on these (Schulz, 2007). For example, numerous intracellular signaling cascades converge with the activation of the protein complexes, NF- $x$ B and AP-1. Both are ubiquitous eukaryotic transcription factors and act independently or coordinately to regulate expression of target genes. They mediate pleiotropic effects on cellular transformation and play critical roles in tumor cell growth, proliferation, angiogenesis, invasion, apoptosis, and survival (Schulz, 2007). The NF- $x$ B family of transcription factors consists of five members, p50, p52, p65 (Rel A), c-Rel, and Rel $\mathrm{B}$, which exist as homo- and hetero-dimers and bind to a common DNA sequence, the $x \mathrm{~B}$-site, within the promoters/enhancers of their target genes. The most commonly encountered dimer in mammalian cells is the p65/p50 dimer (Pereira and Oakley, 2008). In most normal cells, the p65/p50 dimer is retained in the cytoplasm as an inactive complex by means of direct binding with specific inhibitors, the I- $x$ B proteins (Pereira and Oakley, 2008). Various cues can lead to the degradation of the I- $x \mathrm{~B}$ proteins resulting in translocation of the active NF- $x \mathrm{~B}$ dimer into the nucleus, where thep65 subunit binds to its cognate sites in the promoter of target genes promoting transcription (Pereira and Oakley, 2008). Cumulative studies confirmed that NF- $x \mathrm{~B}$ is constitutively active in CRC and its activation is correlated to tumor growth, progression, aggressive behaviors and poor prognosis. Furthermore, it confers CRC cells resistance to the apoptosis induced by various chemotherapeutic agents (Lind et al., 2000; Hardwick et al., 2001). NF- $x$ B is also known to facilitate angiogenesis, invasion and metastasis in colon cancer tumor cells by up-regulating expression of VEGF, COX-2, interleukine- 6 and matrix metalloproteinases (Kim et al., 2014). Thereby, NF-xB has been described as a major culprit and agents that can suppress NF- $x$ B activation have the potential to suppress carcinogenesis and thus have therapeutic potential. Indeed, many biologically active natural products derived from plant foodshave been found to target NF- $x \mathrm{~B}$ in different cancer cell lines (Ban et al., 2007; Kim et al., 2014). Similar to these compounds, we found that CAERS treatments down-regulated transcriptional activity of a reporter gene driven by NF- $x$ B response elements via inhibiting DNAbinding activity of the p65 subunit. These observations indicate that CAERS has a direct impact on the activity of $\mathrm{NF}-\varkappa \mathrm{B}$ and thus has therapeutic potential. It is documented that NF- $x \mathrm{~B}$ contributes to chemoresistance of cancer cells primarily through upregulation of its down-stream effectors that promote survival of tumor cells (Sethi et al., 2008). The Western blot analyses explained that CAERS down-regulated expression of genes known to be targeted by NF- $x \mathrm{~B}$ and have pro-survival role; these include Survivin, COX-2, Bcl-2, cyclin D1, and VEGF (Sethiet al., 2008). Down-regulation of Survivin by CAERS is seminal findings for many reasons, since Survivin is a member of the inhibitor-of-apoptosis protein family (Reed, 2000), selectively expressed in most human neoplasms including CRC and confers cytoprotection against a variety of apoptotic stimuli (Altieri, 2003). In response to cell death stimulation, it interferes with caspase-3/7 activation and inhibits apoptosis (Altieri, 2003). Importantly, Survivin promotes cell proliferation and cell cycle progression by activating the CDK4/cyclinD1 complex (Altieri, 2003), which would boost proliferation of CRC cells. Likewise, abundant evidences support the role of COX-2 in the CRC progression (Pandurangan and Esa, 2013) and many natural compounds have been found to suppress CRC growth in vivo and in vitro systems by modulating COX-2 level Pandurangan et al., 2013; Wang et al., 2013; Chidambara et al., 2012). Therefore, down-regulation of Survivinand COX-2 by CAERS indicates that CAERS could effectively target survival advantage provoked by over-expression of these proteins in HCT116 cells.

Various agents that activate NF- $x \mathrm{~B}$ also activate AP-1 (Gopalakrishnan and Kong, 2008). AP-1 molecule encompasses heterodimeric protein complexes including products of the proto-oncogene Jun gene (c-Jun, JunB and JunD) and Fos (c-Fos, FosB, Fra-1 and Fra-2) proto-oncogene (Hess et al., 2004). A growing list of evidences demonstrates thatAP-1has a direct role in tumourigenesis, progression, invasion and metastasis of CRC. This is because AP-1 was found to be highly expressed in the stroma surrounding the tumor in the majority of cases (Vaiopoulos et al., 2010). Furthermore, high concentrations of bile acids induce AP-1 expression 
and its downstream targets COX-2 and VEGF, which are responsible for invasiveness, metastasis and angiogenesis in colon cancer tumors (Debruyne et al., 2001; Liu et al., 2009). AP-1 also mediates the anti-apoptotic response to the hypoxic conditions encountered in the solid tumors which contributed to their resistance to chemotherapy and radiotherapy (Shaulian and Karin, 2002). Therefore, the agents having a potentiality to inhibit the AP-1 transcriptional activity are considered ideal candidates for treatment of CRC. Our results demonstrated that CAERS treatments resulted in down-regulation of a reporter gene driven by AP-1 response elements correlating with inhibition of DNA-binding activity of the AP-1 dimer subunits, c-Fos and JunD, in a dose-dependent manner. Therefore, these results suggest that CAERS could target the survival signaling pathway directed by AP-1, which could be partially responsible for apoptogenic potentiality of CAERS leading to growth-inhibition of HCT116 cells.

Other importance of CAERS activity could be concluded from results showing activation of Nrf-2, a master regulator of the cytoprotective genes. Nrf2 is an important cytoprotective transcription factor (Lee and Johnson, 2004). It plays a pivotal role in coordinating the cytoprotection response through mediating induction of the ARE-genes (Hayes et al., 2010), which makes it a promising target for cancer chemoprevention (Wenge et al., 2008). It has been found that some phytochemicals exert their anti-cancer effect by repression of NF- $x \mathrm{~B}$ and its target genes with a concomitant activation of the Nrf2-ARE pathway. Indeed, many examples indicate that activation and repression occur between members of the two pathways at multiple levels of interaction (Manna et al., 2014; Nagle et al., 2014; Surh, 2008). In addition, the data obtained from animal studies underlined the possibility that Nrf2 exerted anti-tumorigenic effect by activation of ARE-gene battery and by suppression of pro-inflammatory pathways mediated by NF- $x$ B signaling (Wenge et al., 2008). Consistent with these studies, we report in this study that CAERS markedly increased the DNA-binding activity of Nrf2, promoted transcription of a reporter gene driven by Nrf2-response elements and up-regulated expression levels of Nrf-2 down-stream effectors, HO1, NQO1 and UGT1A1. These observations suggest that CAERS has a potentiality to confer cytoprotection response through mediating induction of the ARE-genes. Similar to CAERS, many phytochemicals have been found to modulate activity of Nrf-2 in CRC cells. For example, oroxylin A has been found to modulate the Nrf2 pathway in HCT116 cells and in xenograft tumors (Hu et al., 2012). Epigallocatechingallate also inhibited growth of colon cancer cells and orthotopic colon cancer by upregulating the Nrf2 and UGT1A expression (Yuan et al., 2007; Zhang et al., 2009). Likewise, Pterostilbene prevented colon tumorigenesis, in vitro and in vivo, via activation of the Nrf2-mediated antioxidant signaling pathway (Chiou et al., 2012; Harun and Ghazali, 2012). Allicin induced apoptosis in CRC cells via Nrf2 (Bat-Chen et al., 2010). Luteolin induced Nrf2 and its downstream targets such as Glutathione-S-transferase and UGT1A1 in AOM-induced colon cancer (Pandurangan et al., 2013).

The transition from one cell cycle phase to another proceeds in an orderly fashion and is regulated by cyclins and cyclin-dependent kinases (CDK) (Vermeulen et al., 2003).

A subclass of cyclins, called cyclin D acts, as a growth sensor and provides a link between mitogenic stimuli and the cell cycle. When cyclin D1 binds to CDK-4/6 in early $\mathrm{G} 1$, the latter is activated leading phosphorylation of key substrate proteins that mediate the transition from G1 to the S phase (Vermeulen et al., 2003). However, the activity of cyclinD1/CDK-4/-6 complex is negatively regulated by endogenous inhibitor proteins p21 and p27. These inhibitors regulate the progression of cells in the G0-G1 phase of the cell cycle and induction of these proteins causes a blockade of the $\mathrm{G} 1$ to $\mathrm{S}$ transition, thereby resulting in a G0-G1 phase arrest of the cell cycle (Vermeulen et al., 2003). Disturbance of this scenario results in an unrestrained cell proliferation, a hallmark of cancer (Hanahan and Weinberg 2011). Accordingly, many natural products have been found to exert their anti-proliferative potentialities through modulating expression of cell cycle regulatory proteins (Meeran and Katiyar, 2008). For example, the indole-3-carbinol has been found to induce cell cycle arrest at the G1/S phase, via down-regulation of cyclin D1, CDK2, CDK4/6 and up-regulation of p21, and p27 and in various cancer cells, including colon cancer, breast cancer, prostate cancer, endometrial cancer, and leukemic cells (Aggarwal and Ichikawa, 2005). Likewise, it has recently been reported that a natural product, Resibufogenin, inhibited HT29 CRC cell line growth and induced G1-phase arrest through degradation of cyclin D1 (Ichikawa et al., 2015). The data herein show that CAERS treatment downregulated expression levels of the cyclin D1 and CDK-4, whilst it enhanced expression of p21 suggesting that the modulation of cyclin D1/CDK-4/p21 complex could be an important molecular mechanism through which CAERS inhibited the proliferation of HCT116 cells.

Other master regulator of the cell cycle is p53, a tumor suppressor gene product, which plays an important role in tumor growth inhibition and induction of apoptosis. The p53 gene is absent or mutated in $85 \%$ of all human colon cancers (Vousden, 2002) and several studies have shown an association between p53 mutation status and sensitivity to chemotherapeutic drugs in CRC and other cancers (O'Connor et al, 1997; Weller, 1998). Thep53 protein triggers the apoptotic machinery through the regulation of the Bax function and mitochondrial integrity, resulting in the release of cytochrome $\mathrm{c}$ and the activation of caspases (Nakano and Vousden, 2001). It has been reported that overexpression of the p53 gene inhibits constitutive activity of NF- $x \mathrm{~B}$ and synergizes with nonsteroidal anti-inflammatory drugs, such as aspirin, to induce apoptosis in human colon cancer cells (Shao et al., 2000). The data in the present study are in accord with these previous studies and suggest that CAERS treatment mediating up-regulation of p53 expression may restrain constitutive activity of NF- $x \mathrm{~B}$ and render HCT116 cells more susceptible to apoptosis. Extending the results from present study into an in vivo study would further provide valuable insights on the bioavailability of CAERS and its mechanistic role in prevention of colon tumorogenesis. 


\section{Acknowledgements}

This study has been supported by King Abdulaziz City for Science and Technology (KACST) by a Research Grant No.AT-32-42. All research works have been carried in the Mutagenicity \&Carcinogenicity Research Unit, King Fahd Medical Research Center and at Department of Biological Sciences, Faculty of Sciences, King Abdulaziz University.

\section{References}

Aggarwal BB, Ichikawa H (2005). Molecular targets and anticancer potential of indole-3-carbinol and its derivatives. Cell Cycle, 4, 1201-15.

Altieri DC (2003). Validating survivin as a cancer therapeutic target" Nat Rev Cancer, 3, 46-54.

Anisz T (2007). Alkaloids: Secrets of Life Alkaloid Chemistry, Biological Significance, Applications and Ecological Role. Elsevier Amsterdam, The Netherlands

Baeshen NA, Elkady AI, Abuzinadah OA, Mutwakil MH (2012). Potential anticancer activity of the medicinal herb, Rhazya stricta, against human breast cancer. African J Biotechnol, 11, 8960-72.

Ban JO, Yuk DY, Woo KS, et al (2007). Inhibition of cell growth and induction of apoptosis via inactivation of NF- $x \mathrm{~B}$ by a sulfur compound isolated from garlic in human colon cancer cells. J Pharmacol Sci, 104, 374-83.

Bat-Chen W, Golan T, Peri I, Ludmer Z, Schwartz B (2010). Allicin purified from fresh garlic cloves induces apoptosis in colon cancer cells via Nrf2. Nutr Cancer, 62, 947-57.

Chidambara MKN, Jayaprakasha GK, Patil BS (2012). The natural alkaloid berberine targets multiple pathways to induce cell death in cultured human colon cancer cells. Eur $J$ Pharmacol, 688, 14-21.

Chiou YS, Ma NJ, Sang S, Ho CT, Wang YJ, Pan MH (2012). Peracetylated (-)-epigallocatechin-3-gallate (AcEGCG) potently suppresses dextran sulfate sodium-induced colitis and colon tumorigenesis in mice. J Agric Food Chem, 60 , 3441-51.

Debruyne PR, Bruyneel EA, Li X, et al (2001). The role of bile acids in carcinogenesis. Mutat Res, 480-481, 359-69.

Dunkern TR, Fritz G, Kaina B (2001). Ultraviolet light-induced DNA damage triggers apoptosis in nucleotide excision repair-deficient cells via Bcl-2 decline and caspase-3/-8 activation. Oncogene, 20, 6026-38.

El Gendy MA, Ali BH, Michail K, Siraki AG, El-Kadi AO (2012). Induction of quinone oxidoreductase 1 Enzyme by Rhazya stricta through Nrf2-dependent mechanism. $J$ Ethnopharmacol, 144, 416-24.

Elkady AI (2013). Crude alkaloid extract of Rhazya stricta inhibits cell growth and sensitizes human lung cancer cells to cisplatin through induction of apoptosis. Genet Mol Biol, 36, $12-21$.

Elkady AI, Hussein RA, Abu-Zinadah AO (2014). Differential Control of Growth, Apoptotic Activity and Gene Expression in Human Colon Cancer Cells by Extracts Derived from Medicinal Herbs, Rhazya stricta and Zingiber officinale and Their Combination. World J Gastroenterol, 20, 15275-88.

Elkady AI, El-Assouli SM, Hussein RAH (2015). Mechanism of Action of (Nigella sativa) on Human Colon Cancer Cells: the Suppression of AP-1 And NF- $x$ B Transcription Factors and the Induction of Cytoprotective Genes. Asian Pac J Cancer Prev, 16, 7943-57.

Eng C (2010). The evolving role of monoclonal antibodies in colorectal cancer: early presumptions and impact on clinical trial development. Oncologist, 15, 73-84.

Fang JY, Richardson BC (2005). The MAPK signaling pathways and colorectal cancer. Lancet Oncol, 6, 322-7.

Gilani SA, Kikuchi A, Shinwari ZK, Khattak ZI, Watanabe KN (2007). Phytochemical, pharmacological and ethnobotanical studies of Rhazya stricta Decne. Phytother Res, 21, 301-7.

Gopalakrishnan A, Kong NT (2008). Anticarcinogenesis by dietary phytochemicals: Cytoprotection by Nrf2 in normal cells and cytotoxicity by modulation of transcription factors NF- $x \mathrm{~B}$ and AP-1 in abnormal cancer cells. Food Chemical Toxicol, 46, 1257-70.

Hanahan D, Weinberg RA (2011). Hallmarks of Cancer: The Next Generation. Cell, 144, 646-74.

Hardwick JC, van den Brink GR, Offerhaus GJ, van Deventer SJ, Peppelenbosch MP (2001). NF- $x$ B, p38 MAPK and JNK are highly expressed and active in the stroma of human colonic adenomatous polyps. Oncogene, 20, 819-27.

Harun Z, Ghazali AR (2012). Potential chemoprevention activity of Pterostilbene by enhancing the detoxifying enzymes in the HT-29 Cell Line. Asian Pac J Cancer Prev, 13, 6403-7.

Hayes JD, McMahon M, Chowdhry S, Dinkova-Kostova AT (2010). Cancer chemoprevention mechanisms mediated through the Keap1-Nrf2 pathway. Antioxid Redox Signal, 13, 1713-48.

Hess J, Angel P, Schorpp-Kistner M (2004). AP-1 subunits: quarrel and harmony among siblings. J Cell Science, 117, 5965-73.

Hu R, Chen N, Yao J, Zhao Q, Zhang F, Li ZY, You QD, Guo QL (2012). The role of Nrf2 and apoptotic signaling pathways in oroxylin A-mediated responses in HCT-116 colorectal adenocarcinoma cells and xenograft tumors. Anticancer Drugs, 23, 651-8.

Ichikawa M, Sowa Y, Iizumi Y, Aono Y, Sakai T (2015). Resibufogenin Induces G1-Phase Arrest through the Proteasomal Degradation of Cyclin D1 in Human Malignant Tumor Cells. PLoS One, 10.

Justin A Call, S Gail Eckhardt, D Ross Camidge (2008). Targeted manipulation of apoptosis in cancer treatment. Lancet Oncol, 9, 1002-11.

Khan N, Afaq F, Mukhtar H (2007). Apoptosis by dietary factors: the suicide solution for delaying cancer grow. Carcinogenesis, 28, 233-9.

Kim MK, Kang YJ, Kim DH, et al (2014). A novel hydroxamic acid derivative, MHY218, induces apoptosis and cell cycle arrest through downregulation of NF- $x$ B in HCT116 human colon cancer cells. Int J Oncol, 44, 256-64.

Kim PJ, Plescia J, Clevers H, Fearon ER, Altieri DC (2003). Survivin and molecular pathogenesis of colorectal cancer. Lancet, 362, 205-9.

Kumar M1, Sharma VL, Sehgal A, Jain M (2012). Protective effects of green and white tea against benzo(a)pyrene induced oxidative stress and DNA damage in murine model. Nutr Cancer, 64, 300-6.

Kundu T1, Bhattacharya RK, Siddiqi M, Roy M (2005). Correlation of apoptosis with comet formation induced by tea polyphenols in human leukemia cells. J Environ Pathol Toxicol Oncol, 24, 115-28.

Kokileva L (1994). Multi-step chromatin degradation in apoptosis. DNA breakdown in apoptosis. Int Arch Allergy Immunol, 105, 339-43.

Lee J-M, Johnson JA (2004). An important role of Nrf2-ARE pathway in the cellular defense mechanism, $J$ Biochem Molecular Biol, 37, 139-43.

Levin B, Lieberman DA, McFarland B, et al (2008). Screening and surveillance for the early detection of colorectal cancer and adenomatous polyps, 2008: a joint guideline from the american cancer society, the us multi-society task force on 
colorectal cancer, and the American College of Radiology. Gastroenterol, 134, 1570-95.

Lind DS, Hochwald SN, Malaty J, et al (2000). Nuclear factor$\varkappa \mathrm{B}$ is upregulated in colorectal cancer. Surgery, 130,363-9.

Liu B, Qu L, Tao H (2009) Cyclo-oxygenase 2 up-regulates the effect of multidrug resistance. Cell Biol Int, 34, 21-5.

Lu JJ, Bao JL, Chen XP, Huang M, Wang YT (2012). Alkaloids isolated from natural herbs as the anticancer agents. Evidence-Based Complementary Alternative Med, 2012, 485042.

Manna K, Khan A, Kr Das D, et al (2014). Protective effect of coconut water concentrate and its active component shikimic acid against hydroperoxide mediated oxidative stress through suppression of NF- $x \mathrm{~B}$ and activation of Nrf2 pathway. $J$ Ethnopharmacol, 155, 132-46.

Marwat SK, Fazal-ur-Rehman, Usman K, Shah SS, Anwar N, Ullah I (2012). A review of phytochemistry, bioactivities and ethno medicinal uses of Rhazya stricta Decsne (Apocynaceae). African J Microbiol Res, 6, 1629-41.

Meerana SM, Katiyara SK (2008). Cell cycle control as a basis for cancer chemoprevention through dietary agents. Front Biosci, 13, 2191-202.

Nagata S (2000). Apoptotic DNA fragmentation. Exp Cell Res, 256, $12-1$.

NagleAA, Reddy SA, Bertrand H, et al (2014).3-(2-Oxoethylidene) indolin-2-one derivatives activate Nrf2 and inhibit NF- $x \mathrm{~B}$ : potential candidates for chemoprevention. Chem Med Chem, 9, 1763-74

Nakano K, Vousden KH (2001). PUMA, a novel proapoptotic gene, isinduced by p53. Mol Cell, 7, 683-94.

O'Connor PM, Jackman J, Bae I, et al (1997). Characterization of the p53 tumor suppressor pathway in cell lines of the National Cancer Institute anticancer drug screen and correlations with the growth-inhibitory potency of 123 anticancer agents. Cancer Res, 57, 4285-300.

Pandurangan, AK, Esa NM (2013). Dietary non-nutritive factors in targeting of regulatory molecules in colorectal cancer: an update. Asian Pac J Cancer Prev, 14, 5543-52.

Pandurangan AK, Kumar SA, Dharmalingam P, Ganapasam S (2014).Inhibitory effect of Luteolin on Azoxymethaneinduced colon carcinogenesis: Involvement of iNOS and COX-2. Pharmacog Magazine, 10, 306-10.

Pereira SG, Oakley F (2008). Nuclear factor- $x$ B1: Regulation and function. Int J Biochemistry Cell Biol, 40, 1425-30.

Rabik CA, Dolan ME (2007). Molecular mechanisms of resistance and toxicity associated with platinating agents. Cancer Treat Rev, 33, 9-23.

Ragnhammar P, Hafstrom L, Nygren P, Glimelius B (2001). A systematic overview of chemotherapy effects in colorectal cancer. Acta Oncol, 40, 282-308.

Reed JC (2000). Mechanisms of apoptosis. Am J Pathol, 157, 1415-30.

Saraste A, Pulkki K (2000). Morphologic and biochemical hallmarks of apoptosis. Cardiovascular Res, 45, 528-37.

Schulz WA, Molecular biology of human cancers: an advanced student's textbook. Springer Science Business Media, Springer Dordrecht, 2007.

Seeram NP, Adams LS, Hardy ML, Herber D (2004). Total cranberry extract versus its phytochemical constituents: antiproliferative and synergistic effects against human tumor cell lines. J Agric Food Chem, 52, 2512-7.

Seeram NP, Adams LS, Henning SM, et al (2005). In vitro antiproliferative, apoptotic and antioxidant activities of punicalagin, ellagic acid and a total pomegranate tannin extract are enhanced in combination with other polyphenols as found in pomegranate juice. J Nutr. Biochem, 16, 360-7.

Sethi G, Sung B, Aggarwal BB (2008). Nuclear Factor- $\varkappa$ B
DOI:http://dx.doi.org/10.7314/APJCP.2016.17.4.1947 Harmal Extract Induces Apoptosis in Colon Cancer Cells

activation: from bench to bedside. ExpBiol Med, 233, 21-31.

Shao J, Fujiwara T, Kadowaki Y, et al (2000). Overexpression of the wild-type p53 gene inhibits NF-kappaB activity and synergizes with aspirin to induce apoptosis in human colon cancer cells. Oncogene, 19, 726-36.

Shaulian E, Karin M (2002). AP-1 as a regulator of cell life and death. Nat Cell Biol, 4, 131-6.

Surh YJ (2008). NF- $x$ B and Nrf2 as potential chemopreventive targets of some anti-inflammatory and antioxidative phytonutrients with anti-inflammatory and antioxidative activities. Asia Pac J Clin Nutr, 17, 269-72.

Vaiopoulos G, Papachroni K, Papavassiliou AG (2010). Colon carcinogenesis: Learning from $\mathrm{NF}-x \mathrm{~B}$ and $\mathrm{AP}-1$. Int $J$ Biochemistry Cell Biol, 42, 1061-5.

Vermeulen K, Van Bockstaele DR, Berneman ZN (2003). The cell cycle: a review of regulation, deregulation and therapeutic targets in cancer. Cell Prolif, 36, 131-49.

Violette S, Poulain L, Dussaulx E, et al (2002). Resistance of colon cancer cells to long-term 5-fluorouracil exposure is correlated to the relative level of Bcl-2 and Bcl-XL in addition to Bax and p53 status. Int J Cancer, 98, 498-504.

Vousden KH (2002). Activation of the p53 tumor suppressor protein. Biochim Biophys Acta, 1602, 47-59.

Wang J, Liu L, Qiu H, et al (2013). Ursolic acid simultaneously targets multiple signaling pathways to suppress proliferation and induce apoptosis in colon cancer cells. PLoS One, $\mathbf{8}$, 63872.

Weller M (1998). Predicting response to cancer chemotherapy: the role of p53. Cell Tissue Res, 292, 435-45.

Wenge Li, Tin Oo Khor, Changjiang Xu, Guoxiang Shen, WooSik Jeong, Siwang Yu, and Ah-Ng Kon (2008). Activation of Nrf2-antioxidant signaling attenuates NF- $\varkappa$ B inflammatory response and elicits apoptosis. Biochem Pharmacol, 76, 1485-9.

Wilkins RC, Kutzner BC, Truong M, Sanchez-Dardon J, McLean JR (2002). Analysis of radiation-induced apoptosis in human lymphocytes: flow cytometry using Annexin V and propidium iodide versus the neutral comet assay. Cytometry, 48, 14-9.

Wong RS (2011). Apoptosis in cancer: from pathogenesis to Treatment. J Experimental Clin Cancer Res, 30, 87.

Yang SY, Sales KM, Fuller B, Seifalian AM, Winslet MC (2009). Apoptosis and colorectal cancer: implications for therapy. Trends Mol Med, 15, 225-33.

Yasuhara S, Zhu Y, Matsui T, et al (2003). Comparison of cometassay, electronmicroscopy, and flowcytometry for detection of apoptosis. J Histochem Cytochem, 51, 873-85.

Yuan JH, Li YQ, Yang XY (2007). Inhibition of epigallocatechin gallate on orthotopic colon cancer by upregulating the Nrf2-UGT1A signal pathway in nude mice," Pharmacol, 80, 269-78.

Zimmermann KC,Bonzon C,R.Green DR (2001). The machinery of programmed cell death. Pharmacol Therapeutics, 92, 57-70.

Zhang ZM, Yang XY, Yuan JH, Sun ZY,Li YQ (2009). Modulation of NRF2 and UGT1A expression by epigallocatechin-3gallate in colon cancer cells and BALB/c mice. Chin Med $J, 122,1660-5$. 